\title{
PENERAPAN MODEL KOOPERATIF LISTENING TEAM UNTUK MENINGKATKAN KUALITAS PEMBELAJARAN PADA MATA KULIAH KIMIA FISIKA I
}

\author{
Maria Erna \\ Program Studi Pend. Kimia FKIP, Universitas Riau, Pekanbaru \\ Email: bun_erna@yahoo.com
}

\begin{abstract}
Abstrak
Telah diterapkan model pembelajaran kooperatif Listening Team untuk meningkatkan kualitas pembelajaran pada Mata Kuliah Kimia Fisika I yang dilakukan pada semester ganjil tahun ajaran 2014/2015. Bentuk penelitian adalah pre-eksperimen dengan rancangan Single one shot Case Study dengan one group pretest-posttest. Hasil penelitian memperlihatkan penerapan model pembelajaran kooperatif tipe Listening Team dapat meningkatkan kualitas pembelajaran pada Mata Kuliah Kimia Fisika I. Hasil kualitas proses pembelajaran mata kuliah Kimia Fisika I memperlihatkan bahwa interaksi mahasiswa dengan sumber belajar menunjukkan tren positif terlihat dari nilai rata-rata Lembar Kerja Mahasiswa (LKM) yang diperoleh mahasiswa setiap pertemuan diatas 80 dan penghargaan kelompok bervariasi setiap pertemuan. Kompetensi atau kemampuan mahasiswa didapatkan berdasarkan penilaian hasil belajar yaitu rata-rata nilai $\mathrm{N}$-Gain sebesar 0,55 termasuk kedalam klasifikasi peningkatan sedang dan tingkat ketuntasan secara klasikal sebesar $60 \%$.
\end{abstract}

Kata Kunci: Kimia Fisika I, Kooperatif, Kualitas, Listening Team, Pembelajaran

\begin{abstract}
It has been applied the cooperative learning model Listening Team to improve the quality of learning in Physical Chemistry I Course on the first semester of the academic year 2014/2015. The research is a pre-experimental research with single one shot case study and one group pretest-posttest design. The research results showed that the application of cooperative learning model Listening Team can improve the quality of learning in the Course of Physical Chemistry I. The results of the quality of the learning process on the subjects of Physical Chemistry I showed that the interaction of students with learning resources are positive trend. The average value of Task Sheet To Students (TSS) was over than 80 for each meetings and group awards varies for each meeting. The competence or ability of students obtained based on the assessment of learning outcomes are an average $\mathrm{N}$-Gain value by 0.55 into in improvement the medium classification and the mastery level in classical by $60 \%$.
\end{abstract}

Keywords: Cooperative, Learning, Listening Team, Physical Chemistry I, Quality

\section{PENDAHULUAN}

Mata kuliah Kimia Fisika I termasuk Mata Kuliah Keahlian Berkarya (MKKB). Adapun materi mata kuliah ini meliputi konsep dasar materi, sifat materi, sifat gas, 
termodinamika I,II dan III. Pada umumnya materi mata kuliah Kimia Fisika I ini penuh dengan konsep-konsep teori yang mempunyai tingkat keabstrakan yang cukup tinggi.

Berdasarkan pengalaman peneliti mengajar mata kuliah Kimia Fisika I sejak tahun 2001 sampai sekarang, tidak banyak mahasiswa yang aktif dalam belajar, baik untuk menjawab pertanyaan maupun mengajukan pertanyaan. Hal ini disebabkan kurangnya rasa percaya akan kemampuan diri sendiri dari mahasiswa tersebut. Akibatnya mahasiswa selalu tidak siap untuk mengikuti ujian dan hasil evaluasi belajar mahasiswa pendidikan kimia pada mata kuliah menunjukkan ketidaktuntasan. Hasil wawancara dengan mahasiswa yang telah mengambil mata kuliah ini, menyatakan bahwa mata kuliah ini sulit untuk dipelajari bahkan divonis sebagai matakuliah yang cukup ditakuti, karena banyaknya konsep-konsep teori yang dijabarkan dalam persamaan atau rumus-rumus matematis.

Untuk mengatasi masalah diatas, diperlukan dosen yang kreatif, yaitu dosen yang mampu membuat pembelajaran Kimia Fisika I menjadi menarik dan disukai mahasiswa serta membangkitkan motivasi mahasiswa sehingga terjadi peningkatan kualitas pembelajaran. Upaya untuk meningkatkan keaktifan belajar mahasiswa salah satunya dapat dilakukan dengan cara menerapkan model pembelajaran sehingga kualitas pembelajaran menjadi meningkat. Kualitas pembelajaran ditentukan berdasarkan penilaian atau evaluasi terhadap hasil belajar mahasiswa. Karena penilaian hasil belajar dapat mengukur seberapa jauh mahasiswa telah menguasai pengetahuan yang dipelajari, dapat memperagakan keterampilannya, dan menunjukkan perubahan dalam sikapnya.

Data kualitas pembelajaran adalah data aktivitas mahasiswa meliputi (1) mengerjakan tugas, (2) kerjasama dalam kelompok, (3) interaksi mahasiswa antar kelompok, (4) interaksi mahasiswa dengan dosen, (5) mengajukan pertanyaan, dan (6) menjawab pertanyaan. Kriteria keberhasilan adalah adanya peningkatan aktivitas pada saat proses belajar mengajar berlangsung.

Pada penelitian ini diterapkan model pembelajaran kooperatif Listening Team. Model pembelajaran ini membantu mahasiswa agar tetap terfokus dan siap siaga selama pelajaran yang diberikan. Tim pendengar menciptakan kelompok-kelompok kecil dengan tugas yang berbeda (penanya, pendukung, penentang dan penarik kesimpulan). Perbedaan tugas setiap kelompok memunculkan diskusi yang aktif (Silberman, 2006).

Menurut Suprijono (2011) langkah-langkah pembelajaran Listening Team: 
1. Bagilah peserta didik menjadi empat tim, dan berilah tim-tim itu tugas- tugas seperti terdapat pada Tabel 1 .

2. Sampaikan pelajaran anda yang didasarkan pada setiap tatap muka. Setelah selesai, berilah waktu kepada masing-masing kelompok waktu untuk mendiskusikan tugastugas mereka.

3. Intruksikan ke setiap tim untuk bertanya, setuju, membantah dan menarik kesimpulan.

Tabel 1. Langkah ListeningTeam

\begin{tabular}{|c|c|c|}
\hline Tim & Peran & Tugas \\
\hline 1 & Penanya & Merumuskan pertanyaan \\
\hline 2 & Pendukung & $\begin{array}{l}\text { Menjawab pertanyaan yang didasarkan pada poin- } \\
\text { poin yang disepakati (membantu dan } \\
\text { menjelaskannya, mengapa demikian) }\end{array}$ \\
\hline 3 & Penentang & $\begin{array}{l}\text { Mengutarakan poin-poin yang tidak disetujui atau } \\
\text { tidak bermanfaat dan menjelaskan mengapa } \\
\text { demikian. }\end{array}$ \\
\hline 4 & Penarik kesimpulan & Menyimpulkan hasil \\
\hline
\end{tabular}

Penerapan model kooperatif Listening Team diharapkan dapat meningkatkan kualitas pembelajaran Kimia Fisika I. Kualitas pembelajaran ditentukan berdasarkan kualitas proses belajar dan hasil belajar. Kualitas proses pada penelitian ini dipelajari berdasarkan nilai Lembar Kerja Mahasiswa (LKM) dan kategori penghargaan kelompok setiap pertemuan atau perkulian. Sedangkan hasil belajar ditentukan berdasarkan nilai $N$ Gain dan ketuntasan yang didapatkan dari nilai postest. Hasil penelitian ini diharapkan dapat digunakan oleh dosen lain untuk memperbaiki kualitas pembelajaran mata kuliah lain.

\section{METODE PENELITIAN}

Penelitian ini telah dilaksanakan di Program Studi Pendidikan Kimia FKIP Universitas Riau, pada semester I tahun ajaran 2014/ 2015 dengan langkah-langkah penelitian sebagai berikut:

a. Penentuan populasi dan Sampel

Populasi pada penelitian ini adalah seluruh mahasiswa program Studi Pendidikan Kimia. Sedangkan sampel pada penelitian ini adalah mahasiswa kelas PGMIPA-U Semester III yang mengambil mata kuliah Kimia Fisika I dengan jumlah 20 orang. 


\section{b. Bentuk Penelitian}

Penelitian merupakan pre-eksperimen yaitu penelitian yang dimaksudkan untuk mengetahui ada tidaknya akibat dari perlakuan yang dikenakan (model pembelajaran kooperatif Listening Team) pada subjek yang diselidiki tanpa adanya variable kontrol dan sampel tidak dipilih secara acak (Sugiyono, 2010).

c. Rancangan Penelitian

Rancangan penelitian yang digunakan adalah Single one shot Case Study dengan one group pretest-posttest. Adapun rancangannya seperti pada Gambar 1.

\begin{tabular}{ll|}
$\mathrm{X}$ & $\mathrm{O}$ \\
\hline
\end{tabular}

$\mathrm{X}$ : Treatment penerapan model Kooperatif Listening Team

$\mathrm{O}$ : Observasi dari penerapan model Kooperatif Listening Team

Gambar 1. Uji coba desain Single one shot Case Study dengan one group pretest-

\section{Posttest.}

d. Instrumen Penelitian

1. Perangkat pembelajaran :

2. Silabus, Rencana Pelaksanaan Pembelajaran (RPP) yang mencakup soal evaluasi

3. Lembar Kerja Mahasiswa (LKM)

4. Instrument pengumpulan data

Instrumen pengumpulan data yang digunakan dalam penelitian ini adalah:

Soal pretest/postest materi Kimia Fisika I

e. Teknik Analisis Data

1. Penentuan $N$-gain

Untuk menunjukkan kategori peningkatan kualitas pembelajaran setelah penerapan model kooperatif dilakukan uji normalitas $(N-$ Gain) dengan persamaan berikut:

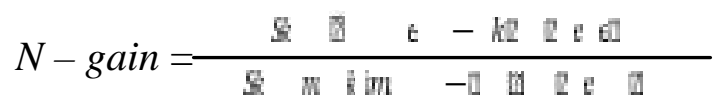

Tabel 2. Nilai N - Gain Ternomalisasi dan Klasifikasi

\section{Rata-rata $N$-Gain \\ Klasifikasi}

Ternormalisasi

\begin{tabular}{cc}
\hline $0,7<\mathrm{N}-$ gain & Tinggi \\
\hline $0,30 \leq \mathrm{N}-$ gain $<0,70$ & Sedang \\
\hline $\mathrm{N}-$ gain $<0,30$ & Rendah \\
\hline
\end{tabular}




\section{Penentuan Ketuntasan Belajar}

Nilai ujian postest dianalisis untuk mengetahui tingkat ketuntasan belajar mahasiswa dengan persamaan sebagai berikut:

Ketuntasan belajar individu $=\frac{\text { Jumlah skor yang dicapai }}{\text { Skor maksimum }} \times 100 \%$

Ketuntasan belajar mahasiswa klasikal $=\frac{\text { Jumlah mahasiswa tuntas individu }}{\text { Jumlah Mahasiswa }} \times 100 \%$

Ketuntasan kompetensi= $\frac{\text { Jumlahmahasiswa yang tuntas }}{\text { Jumlahtotal mahasiswa }} \times 100 \%$

Ketuntasan kompetensi sec ara klasikal $=\frac{\text { Jumlah kompetensi yang tuntas }}{\text { Jumlah kompetensi umum }} \times 100 \%$

\section{HASIL DAN PEMBAHASAN}

a. Kualitas proses pembelajaran

Hasil kualitas proses pembejaran mata kuliah Kimia Fisika pada didapatkan dari penilaian Lembar Kerja Mahasiswa (LKM) dan penghargaan kelompok setiap pertemuan atau perkuliahan yang berasal dari nilai evaluasi diakhir pertemuan. Proses belajar tidak hanya terjadi karena adanya interaksi antara mahasiswa dengan dosen tetapi juga lewat interaksi antara mahasiswa dengan sumber-sumber belajar. Hasil penelitian memperlihatkan interaksi mahasiswa dengan sumber belajar menunjukkan tren positf terlihat dari nilai rata-rata LKM yang diperoleh mahasiswa setiap pertemuan diatas 80 dapat dilihat pada Gambar 2.

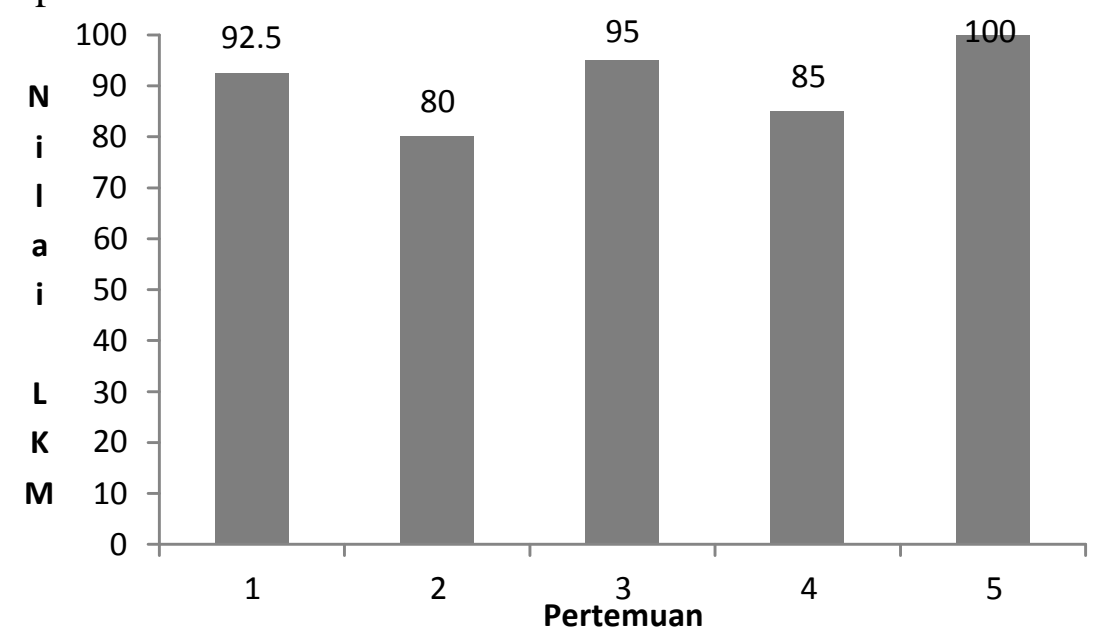

Gambar 2. Nilai Lembar Kerja Mahasiswa (LKM) setiap pertemuan 
Hasil ini didapatkan karena model pembelajaran listening team diterapkan dalam kelompok-kelompok kecil yang dapat mengeksplorasi potensi atau kemampuan setiap mahasiswa untuk berdiskusi dengan cara membuat pertanyaan, menjawab, menantang dan menyimpulkan pembelajaran.

Adanya pembagian tugas pada model pembelajaran listening team menjadikan mahasiswa menjadi aktif dan memiliki pengetahuan lebih mendalam. Tugas-tugas kelompok yang diberikan merangsang mereka untuk beradu dan mengemukakan pendapat sehingga mahasiswa turut berpartisipasi aktif dalam proses pembelajaran. Partisipasi mahasiswa berupa mengamati, bertanya, menjelaskan, dan mengemukakan ide. Dengan berpartisipasi mahasiswa dapat memahami pelajaran dari pengalamannya sehingga dapat meningkatkan hasil belajarnya.

Setiap kegiatan penutup pada proses pembelajaran selalu dilakukan kegiatan evaluasi untuk menilai sejauh mana pencapaian mahasiswa terhadap materi yang telah disampaikan. Kualitas proses pembelajaran dapat meningkat juka dilakukan pemberian penghargaan kelompok pada setiap pertemuan. Penghargaan kelompok ditentukan dari skor rata-rata perkembangan individu anggota kelompok berdasarkan selisih perolehan skor dasar dengan skor evaluasi setiap pertemuan. Setiap anggota kelompok berhak menyumbangkan poin yang akan menentukan tingkat penghargaan untuk kelompok masing-masing. Penghargaan kelompok dapat dilihat pada Tabel 3.

Tabel 3. Penghargaan kelompok setiap pertemuan

\begin{tabular}{cccccc}
\hline Kelompok & \multicolumn{5}{c}{ Penghargaan kelompok/Pertemuan } \\
\cline { 2 - 5 } & 1 & 2 & 3 & 4 & 5 \\
\hline 1 & Super & Hebat & Hebat & Super & Hebat \\
\hline 2 & Super & Hebat & Hebat & Hebat & Hebat \\
\hline 3 & Super & Hebat & Biak & Super & Baik \\
\hline 4 & Super & Hebat & Hebat & Baik & Hebat \\
\hline 5 & Super & Baik & Hebat & Hebat & Baik \\
\hline
\end{tabular}

Adanya penghargaan kelompok membuat setiap anggota kelompok merasa bertanggung jawab untuk keberhasilan kelompoknya. Hal ini sesuai dengan pendapat Roger dan David Jhonson dalam Lie (2007) yang mengungkapkan bahwa setiap anggota kelompok bertanggung jawab untuk menguasai materi pelajaran karena keberhasilan belajar 
kelompok ditentukan dari seberapa besar sumbangan hasil belajar perorangan. Oleh sebab itu mahasiswa termotivasi dalam mengerjakan evaluasi dengan sebaik-baiknya agar kelompoknya mendapat penghargaan.

Hasil penelitian memperlihatkan bahwa pada pertemuan I didapatkan semua kelompok mendapatkan kategori super semuanya, tetapi pada pertemuan berikutnya penghargaan kelompok bervariasi setiap kelompok. Hal ini disebabkan karena kemampuan mahasiswa memahami soal-soal evaluasi berbeda-beda dan tingkat kesulitan kompetensi yang akan dicapai juga semakin meningkat.

b. Kualitas hasil belajar

Kualitas hasil belajar didapatkan berdasarkan kategori $N$-Gain dan ketuntasan belajar mahasiswa. Kategori $N$-Gain berasal dari perbedaan nilai postest dan pretest setiap mahasiswa, sedangkan ketuntasan belajar berasal dari nilai postest. Peningkatan hasil belajar berdasarkan hasil $\mathrm{N}$-Gain dapat dilihat pada Tabel 4.

Tabel 4. Nilai $N$-Gain

\begin{tabular}{|c|c|c|c|c|c|}
\hline \multirow{2}{*}{$\begin{array}{c}\text { Jumlah Mahasiswa } \\
\text { (Orang) }\end{array}$} & \multirow{2}{*}{$\begin{array}{c}\text { Rata- } \\
\text { rata } N- \\
\text { Gain }\end{array}$} & \multirow{2}{*}{$\begin{array}{l}\text { Klasifikasi } N- \\
\text { Gain rata-rata }\end{array}$} & \multicolumn{3}{|c|}{ Jumlah Mahasiswa (Orang) } \\
\hline & & & Tinggi & Sedang & Rendah \\
\hline 20 & 0,55 & Sedang & 3 & 14 & 3 \\
\hline
\end{tabular}

Kompetensi atau kemampuan mahasiswa didapatkan berdasarkan penilaian hasil belajar. Berdasarkan kategori $\mathrm{N}$-Gain setiap pertemuan, rata-rata nilai $\mathrm{N}$-Gain yang diperoleh oleh mahasiswa yang mengambil mata kuliah Kimia Fisika pada semester ganjil 2014/2015 adalah 0,55 dengan peningkatan prestasi dalam klasifikasi sedang. Jumlah mahasiswa yang berkategori tinggi berjumlah 3 orang dan berkategori sedang berjumlah 14 orang serta berkategori rendah berjumlah 3 orang. Hasil ini memperlihatkan bahwa mahasiswa sebelum dilakukan postest tidak termotivasi untuk belajar secara individu dilingkungannya masing-masing, karena perlakuan model pembelajaran listening team hanya diterapkan dikelas.

Menurut Johnson (2009), ada beberapa cara yang dapat dilakukan untuk meningkatkan motivasi belajar mahasiswa yang dapat diterapkan:

1. Bantu mahasiswa menyakini bahwa keberhasilan itu suatu yang mungkin

2. Kenali sikap mahasiswa 
3. Memperbaiki sikap diri sendiri sebelum memperbaiki sikap mahasiswa

4. Tambahkan kegiatan otak-kanan dan kinestetik

5. Minta tanggapan mahasiswa sesering mungkin

6. Ajarkan keterampilan pencarian solusi

7. Ajarkan mahasiswa cara berdebat secara efektif

8. Ajarkan mahasiswa cara bicara kepada dosen atau orang dewasa lainnya

9. Ciptakan tantangan

10. Jadikan kesalahan suatu yang bisa diterima

11. Ubah persepsi mahasiswa atas diri mereka sendiri

Keberhasilan mahasiswa dalam belajar dapat dilihat dari pencapaian hasil belajar yang diperoleh. Pada penelitian ini ditentukan ketuntasan belajar secara individu. Hasil kesepakatan dengan tim pengajar ditetapkan Kriteria Ketuntasan Minimal (KKM) untuk mata kuliah Kimia Fisika adalah dengan nilai 60. Pada Tabel 5, terlihat mahasiswa yang mencapai KKM sebanyak 12 orang dengan tingkat ketuntasan secara klasikal sebesar 60 $\%$. Artinya proses pembelajaran yang dilakukan dengan menerapkan model pembelajaran listening team tingkat keberhasilnya untuk meningkatkan kualitas pembelajaran Kimia Fisika I hanya $60 \%$.

Tabel 5. Hasil ketuntasan belajar secara klasikal.

\begin{tabular}{cccc}
\hline \multirow{2}{*}{$\begin{array}{c}\text { Jumlah Mahasiswa } \\
(\text { Orang) }\end{array}$} & \multicolumn{2}{c}{$\begin{array}{c}\text { Jumlah Mahsiswa } \\
\text { (Orang) }\end{array}$} & $\begin{array}{c}\text { Ketuntasan belajar } \\
\text { secara klasikal }\end{array}$ \\
\cline { 2 - 3 } & Tuntas & Tidak Tuntas & \\
\hline 20 & 12 & 8 & $60 \%$ \\
\hline
\end{tabular}

Hasil ketuntasan berdasarkan kompetensi pada materi Kimia Fisika I dapat dilihat pada Tabel 6, terlihat ketuntasan kompetensi secara klasikal mencapai 64,17\%. Hasil ini diperoleh karena bedasarkan analisis ketuntasan setiap kompetensi terlihat kompetensi materi nomor 1 - 4 dibawah 90\% karena materinya sudah lama dipelajari yaitu dilaksanakan pada pertemuan 2-4 sehingga mahasiswa kesulitan mempelajari kembali materi Kimia Fisika I pada pertemuaan tersebut secara individu. Hal ini terbukti dari kompetensi materi nomor 5 dan 6 kompetensinya diperoleh diatas 90\%. Untuk memperbaiki hasil belajar menurut Kunandar (2013), instrumen penilaian yang digunakan harus valid dan realibel. Artinya dari segi penyusunan telah memenuhi kaidahkaidah penulisan soal, baik dari aspek konstruksi, substansi maupun materi. 
Tabel 6. Hasil ketuntasan berdasarkan kompetensi

\begin{tabular}{ccc}
\hline Kompetensi & $\begin{array}{c}\text { Jumlah mahasiswa tuntas } \\
(\text { Orang })\end{array}$ & $\begin{array}{c}\text { Ketuntasan kompetensi } \\
(\%)\end{array}$ \\
\cline { 2 - 3 } & 10 & 50 \\
\hline 2 & 9 & 45 \\
\hline 3 & 14 & 70 \\
\hline 4 & 7 & 35 \\
\hline 5 & 18 & 90 \\
\hline 6 & 19 & 95 \\
\hline Ketuntasan kompetensi secara klasikal & 64,17 \\
\hline
\end{tabular}

\section{KESIMPULAN}

Berdasarkan hasil dan pembahasan dapat dibuat kesimpulan sebagai berikut:

1. Model pembelajaran kooperatif Tipe Listening Team dapat diterapkan untuk meningkatkan kualitas proses pembelajaran pada mata kuliah Kimia Fisika I dengan nilai LKM setiap pertemuan diatas 80 .

2. Peningkatan kualitas hasil belajar berdasarkan nilai rata-rata $N$-Gain setelah diterapkan model pembelajaran kooperatif Tipe Listening Team termasuk kedalam klasifikasi sedang

3. Ketuntasan belajar mahasiswa pada mata kuliah Kimia Fisika I secara klasikal setelah diterapkan model pembelajaran kooperatif Tipe Listening Team mencapai $60 \%$

4. Ketuntasan kompetensi pada mata kuliah Kimia Fisika I secara klasikal setelah diterapkan model pembelajaran kooperatif Tipe Listening Team mencapai $64,17 \%$

\section{Ucapan Terima Kasih}

Terima kasih kepada DP3M Dirjen Dikti melalui Hibah Program PGMIPA Unggulan Jurusan Pendidikan MIPA Fakultas Keguruan dan Ilmu Pengetahuan Universitas Riau yang telah membiayai penelitian ini pada tahun 2014.

\section{DAFTAR PUSTAKA}

Johnson, L. 2009, Pengajaran yang Kreatif dan Menarik, PT. Indeks, Indonesia Kunandar, 2013, Penilaian Autentik, PT. Rajagrafindo Persada. Jakarta Lie, A, 2007, Cooperative Learning, Grasindo, Jakarta.

Silberman, Mel, 2006, Active Learning. Insan Madani, Yogyakarta 
Sugiyono, 2010, Metode Penelitian Kuantitatif, Kualitatif dan $R \& D$, Bandung Suprijono, Agus, 2011, Cooperative Learning, Pustaka Pelajar, Yogyakarta. 